\title{
Association of PLIN2 polymorphisms with economic traits in Berkshire pigs
}

\author{
Yesong Kim ${ }^{1}$, Jiyeon Seong ${ }^{2}$, Yoonseok Lee ${ }^{2}$ and Hong Sik Kong ${ }^{1,2,3, *}$ \\ ${ }^{1}$ The Graduate School, Department of Animal Life and Environment Science, Hankyong National University, Anseong \\ 17579, Korea \\ ${ }^{2}$ Genomic Informatics Center, Hankyong National University, Anseong 17579, Korea \\ ${ }^{3}$ Gyeonggi-do Regional Research Center, Hankyong National University, Anseong 17579, Korea
}

Received June 15, 2020

Revised August 26, 2020

Accepted September 1, 2020

*Correspondence

Hong Sik Kong

E-mail: Kebinkhs@hknu.ac.kr

ORCID

https://orcid.org/0000-0003-1144-016X

\begin{abstract}
Meat and carcass quality attributes are important factors influencing consumer preference and profitability in the pork industry. Single nucleotide polymorphisms (SNPS) are essential for livestock breeding and improvement. In the present study, the pig Perilipin 2 (PLIN2) gene was characterized with the aim of detecting genetic variation at these loci in relation to economic traits in Berkshire pigs. Four SNPs (G6714C, G6813A, G10340A, and G10632A) were detected in this studied. Statistical analysis indicated that G6714C was significantly associated with the National Pork Producers Council (NPPC) color score, G6813A, and G10340A significantly affected NPPC color score and NPPC marbling score, and G10632A significantly affected backfat thickness (BF) $(p<0.05)$. Therefore, the molecular markers used in the present study might provide a useful basis for identification and improvement of traits in the Berkshire pigs.
\end{abstract}

Keywords: Berkshire, economic traits, PLIN2, SNPS

\section{INTRODUCTION}

Pigs have been domesticated for over 9,000 years, and they are one of the most important farm animals today. The swine industry has focused on improving pork production.

In Korea, for the genetic improvement of Korean Berkshire pigs, selection should simultaneously consider productive, meat quality and reproductive traits, which requires the precise estimation of genetic parameters (Lee et al., 2015)

Meat quality is a major factor affecting palatability. Therefore, the improvement of meat quality traits to meet the rapidly growing demand of consumers is one of the most important targets of breeding farm animals. Meat quality is determined by several factors, including intramuscular fat (IMF) content, water-holding capacity, tenderness, and meat color (Rosenvold and Andersen, 2003). In general, IMF content correlates with meat tenderness and marbled meat is a highly favored product in Korea (Lee et al., 2010).

Meat quality traits are controlled by multiple genes on the chromosomal regions known as quantitative trait loci (QTL). Recently, several studies have reported molecular markers in the candidate genes associated with economic traits. The candidate gene approach is an effective tool for selecting animals with desirable economic traits (Cheong et al., 2006; Oh et al., 2011).

Perilipin 2 (PLIN2), which is a member of the family of perilipin lipid droplets coating proteins, is very widely 
expressed. PLIN2 gene (Accession No. NC_010443.5) consists of eight exons and spans approximately 25,411 bp on Sus scrofa autosome 1. Recently, several studies have reported that PLIN2 ablation protects mice against diet-induced obesity, adipose inflammation, and fatty liver disease by reducing hepatic lipid accumulation, without changes in TAG synthesis, fatty acid uptake, or $\beta$-oxidation (Chang et al., 2006; McManaman et al., 2013).

The present study aimed to detect novel single-nucleotide polymorphisms (SNPs) within the PLIN2 gene by sequencing and determine the genetic association between the molecular markers and economic traits, such as meat quality and carcass traits.

\section{MATERIALS AND METHODS}

\section{Sample collection and genomic DNA extraction}

A total of 103 Berkshire pigs (41 sows and 62 boars) were used for the association study. Meat quality traits were studied. Genomic DNA from tissue samples was extracted using a Toyobo Mag Extractor Kit (Toyobo, Japan), according to the manufacturer's instructions. The DNA was quantified by NanoDrop ND-1000 UV-Vis Spectrophotometer (NanoDrop Technologies, USA).

\section{Carcass and meat quality measurement}

Slaughtering followed standard procedures under the supervision of a Korean grading service for animal prod- ucts. After slaughter, 103 pigs were used for the analysis and a total of 13 traits including: carcass weight (CW), backfat thickness (BF), pH value after 45 minutes (pH45m), $\mathrm{pH}$ value after 24 hours (pH24h), meat color L, a, b, filterpaper fluid uptake (FFU), drip loss (DL), cooking loss (CL), muscle shear force (SF) national pork producers council (NPPC) color score and NPPC marbling score. Following slaughter, the $\mathrm{CW}$ was recorded and the $\mathrm{BF}$ was measured between the 10th and 11th ribs. The $\mathrm{pH}$ was measured 45 min and $24 \mathrm{~h}$ after slaughter. Meat color was measured using three coordinates from the Hunter L, a, b system, where " $\mathrm{L}$ " is a general indication of lightness, "a" represents the degree of redness, and " $b$ " represents the degree of yellowness. To measure FFU (Kauffman et al., 1986), the filter paper was pre-weighed, placed on the surface of a sample to absorb the fluids, and was then weighed again. DL during vacuum storage was determined one day after slaughter by weighing samples before and after storage. CL was measured as the difference between sample weights before and after incubation at $75^{\circ} \mathrm{C}$ for $10 \mathrm{~min}$. SF was determined using a Warner-Bratzler shear force meter (G-R Electrical, USA). The surface color and marbling scores of each loin was categorized based on NPPC standard, NPPC color standards (1 to 6) and marbling [1 (1.0\% IMF) to 10 (10\% IMF)] were evaluated according to the NPPC (2000). The means, standard deviations, and ranges of the 13 traits are shown in Table 1.

Table 1. Mean, standard deviation (SD), minimum (Min), and maximum (Max) of meat quality traits in Berkshire pigs

\begin{tabular}{lrrrr}
\hline & \multicolumn{1}{c}{ Trait $^{\mathrm{a}}$} & Mean & Min & Max \\
\hline CW & 87.019 & 4.555 & 77.0 & 101.0 \\
BF & 22.738 & 4.130 & 13.0 & 35.0 \\
pH45 & 6.130 & 0.308 & 5.3 & 6.7 \\
pH24 & 5.761 & 0.161 & 5.3 & 6.3 \\
Color L & 50.592 & 2.760 & 44.2 & 56.7 \\
Color a & 16.927 & 1.147 & 13.9 & 20.0 \\
Color b & 5.930 & 1.169 & 3.2 & 8.3 \\
FFU & 46.505 & 19.986 & 10.0 & 120.0 \\
DL & 4.064 & 2.366 & 0.2 & 13.2 \\
CL & 17.906 & 3.475 & 10.0 & 25.6 \\
SF & 2.821 & 0.758 & 1.5 & 5.5 \\
NPPC color score & 3.521 & 0.600 & 1.9 & 4.8 \\
NPPC marbling score & 2.065 & 0.537 & 1.0 & 3.7 \\
\hline
\end{tabular}

CW: carcass weight, BF: backfat thickness, pH45: pH recorded 45 min after slaughter, $\mathrm{pH} 24$ : $\mathrm{pH}$ at $24 \mathrm{~h}$ after slaughter, color L: brightness, color a: redness, color b: yellowness, FFU: filter-paper fluid uptake, DL: drip loss, CL: cooking loss, SF: shear force, NPPC: National Pork Producers Council. 


\section{Primer design and polymerase chain reaction (PCR)}

Primers used in the present study were based on the nucleotide sequence of the Pig PLIN2 gene available in the GenBank database (Accession No. NC_010443.5). Detailed information on oligonucleotide primers, amplicon size, and corresponding annealing temperature has been provided in Table 2. PCR amplification was performed using genomic DNA (20-200 ng/ $\mu \mathrm{L}), 10$ pmole of each primer, $2 \mu \mathrm{L}$ of $10 \mathrm{X}$ buffer $(10 \mathrm{mM}$ Tris- $\mathrm{HCl}, 50 \mathrm{mM} \mathrm{KCl}, 1.5 \mathrm{mM}$ $\left.\mathrm{MgCl}_{2}, \mathrm{pH} 8.3\right), 40 \mu \mathrm{M}$ dNTPs, and 0.5 units Taq polymerase (Genetbio, Korea). Thermal cycling included an initial denaturation step of $94^{\circ} \mathrm{C}$ for $5 \mathrm{~min}$, followed by 35 cycles of $94^{\circ} \mathrm{C}$ for $1 \mathrm{~min}$, optimized annealing temperature (see Table 2) for $30 \mathrm{~s}$, and $72^{\circ} \mathrm{C}$ for $30 \mathrm{~s}$, and a final extension at $72^{\circ} \mathrm{C}$ for 5 min using a GeneAmp PCR System 9700 (Applied Biosystems, USA).

\section{Sequencing analysis}

The amplified PCR product of each sample was excised from a 2.0\% agarose gel and purified with AccuPrep ${ }^{\circledR}$ Gel Purification Kit (Bioneer ${ }^{\mathrm{TM}}$, Korea). The purified products were sequenced using BigDye Terminator v3.1 Cycle Sequencing Kit (Applied Biosystems, USA). Sequencing reactions were purified by Ethanol and run on ABI $3130 \mathrm{XL}$ Genetic Analyzer (Applied Biosystems, USA) to determine nucleotide sequences. SNPs were detected with the software Seq Man II (DNA Star, USA).

\section{Statistical analysis}

Statistical analysis of the association of the genotypes based on the molecular markers with the economic traits was evaluated with a general linear model (GLM) fit by the least squares method using the SAS software package (SAS institute, USA). The GLM used in the present study was

$$
Y_{i j}=\mu+G_{i}+\beta A+S_{i}+e_{i j} \text {, }
$$

where $Y_{i j}$ is the observation of the performance traits, $\mu$ is the overall mean for each trait, $G_{i}$ is the $i$-th level of the fixed factor genotype, $\beta$ is the regression coefficient

Table 2. Nucleotide sequences of primer pairs used for PCR amplification of PLIN2

\begin{tabular}{llcc}
\hline \multicolumn{1}{c}{ Primer name } & \multicolumn{1}{c}{ Sequence (5'-3') } & Tm ('C) & Size \\
\hline PLIN2_1 & F-TGAGCCATCTTGGGAAAGG & 55 & 316 \\
& R-CCAGGTTGACAGTGGAATGG & & \\
PLIN2_2 & F-CCTCCTCAGTTCCAGCAAGG & 61 & 714 \\
& R-GCAAGCCACACATAAAGCAC & & \\
\hline
\end{tabular}

for age, $A$ is the age, $S_{i}$ is the $i$-th sex effect, and $e_{i j}$ is the random error for the $\mathrm{ij}$-th individual.

\section{RESULTS}

\section{SNP genotyping of PLIN2 gene in Berkshire pigs}

The DNA samples from 103 Berkshire pigs were amplified and sequenced for the porcine PLIN2 gene. Four polymorphic sites (SNPs) were identified by sequencing analysis of the Berkshire pigs DNA. The 2 pairs of the PLIN2 gene were designed for the SNP genotyping of these SNPs on genomic DNA samples.

We identified four SNPs (G6714C, G6813A, G10340A, and G10632A) in the Berkshire pig PLIN2 gene. Among the for, one SNP (G6714C) was detected in the intron 5 region, one SNP (G6813A) was detected in the exon 6 region, one SNP (G10340A) was detected in the exon 8 region, and one SNP (G10632A) was detected 3'UTR region (Fig. 1). The G6813A displayed a change in amino acid 218 of the PLIN2 protein from valine (V) to isoleucine (I). The G10340A exhibited a change of amino acid 435 of PLIN2 form arginine (R) to histidine (H) (Table 3).

The frequency of $\mathrm{G} 6714 \mathrm{C}$ polymorphism in allele $\mathrm{G}$ was higher than that for allele $C$, and $0.728,0.223$, and 0.049 for the genotypes GG, GC, and CC, respectively. In addition, the other genotype frequencies were as follows: 0.627 (GG) 0.324 (GA), and 0.049 (AA) for G6813A, 0.622 (GG), 0.327 (GA) and 0.051 (AA) for G10340A, and 0.673 (GG), 0.306 (GA), and 0.020 (AA) for G10632A in PLIN2 gene (Table 3).

\section{Association between molecular marker and carcass traits}

To investigate the effects of SNPs, we performed association analysis of PLIN2 genotypes to determine their effects on variations in economic traits. The SNPs G6714C was associated with a significant effect on NPPC color score, the GC (3.80 \pm 0.12$)$ genotype had a higher NPPC

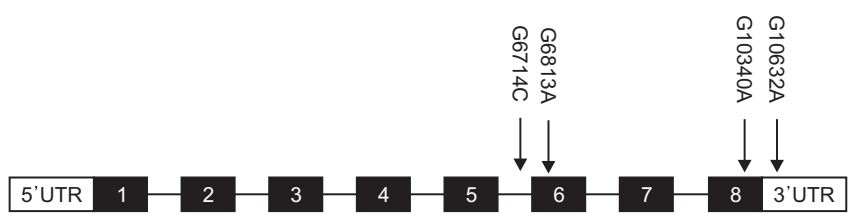

Fig. 1. Structure of the PLIN2 gene and SNPs detected in the Berkshire pigs. 
Table 3. Genotype and allele frequencies of the identified PLIN2 gene in Berkshire pigs

\begin{tabular}{|c|c|c|c|c|c|c|}
\hline Locus & Amino acid change & \multicolumn{3}{|c|}{ Genotype frequency } & \multicolumn{2}{|c|}{ Allele frequency } \\
\hline G6714C & & GG & $\mathrm{GC}$ & $\mathrm{CC}$ & G & $C$ \\
\hline \multirow[t]{2}{*}{ G6813A } & V218I & GG & GA & $A A$ & G & $A$ \\
\hline & & 0.627 & 0.324 & 0.049 & 0.789 & 0.211 \\
\hline \multirow[t]{2}{*}{ G10632A } & & GG & GA & AA & G & A \\
\hline & & 0.673 & 0.306 & 0.020 & 0.827 & 0.173 \\
\hline
\end{tabular}

Table 4. Association of the polymorphisms in the PLIN2 gene with individual traits in Berkshire pigs

\begin{tabular}{|c|c|c|c|c|c|}
\hline \multirow{2}{*}{ Locus } & \multirow{2}{*}{ Trait } & \multicolumn{3}{|c|}{ Genotype frequency } & \multirow{2}{*}{$p$} \\
\hline & & AA & $A B$ & BB & \\
\hline G6714C & NPPC color score & $3.15 \pm 0.06$ & $3.80 \pm 0.12$ & $3.28 \pm 0.25$ & $<0.05$ \\
\hline \multirow[t]{2}{*}{ G6813A } & NPPC color score & $3.38 \pm 0.07$ & $3.73 \pm 0.10$ & $3.40 \pm 0.25$ & $<0.05$ \\
\hline & NPPC marbling score & $2.46 \pm 0.236$ & $1.94 \pm 0.092$ & $2.08 \pm 0.065$ & $<0.05$ \\
\hline \multirow[t]{2}{*}{ G10340A } & NPPC color score & $3.36 \pm 0.07$ & $3.75 \pm 0.10$ & $3.41 \pm 0.26$ & $<0.05$ \\
\hline & NPPC marbling score & $2.46 \pm 0.233$ & $1.91 \pm 0.092$ & $2.07 \pm 0.065$ & $<0.05$ \\
\hline G10632A & $\mathrm{BF}$ & $22.15 \pm 0.49$ & $24.27 \pm 0.71$ & $25.00 \pm 2.75$ & $<0.05$ \\
\hline
\end{tabular}

BF: back fat thickness, NPPC: National Pork Producers Council.

color score than that in the CC $(3.28 \pm 0.25)$ and GG $(3.15 \pm 0.06)$ genotype $(p<0.05)$. G6813A, and G10340A significantly effect NPPC color score and NPPC marbling score $(p<0.05)$. The GA $(3.73 \pm 0.10,3.75 \pm 0.10)$ genotype had a higher NPPC color score than that in the AA $(3.40 \pm 0.25,3.41 \pm 0.26)$ and GG genotype $(3.38 \pm 0.07$, $3.36 \pm 0.07) ; \mathrm{GG}(2.46 \pm 0.236,2.46 \pm 0.233)$ genotype had a higher NPPC marbling score than that in AA (2.08 $\pm 0.0 .065,2.07 \pm 0.065)$ and GA $(1.94 \pm 0.092,1.91 \pm$ $0.092)$ genotype. In addition G10632A significantly affected BF $(p<0.05)$, the AA $(25.00 \pm 2.75)$ genotype had thicker than GA $(24.27 \pm 0.71)$ and GG $(22.15 \pm 0.49)$ genotype (Table 4).

\section{DISCUSSION}

We identified four SNPs in Berkshire pigs PLIN2 gene; one SNP (G6714C) was detected in the intron 5 region, one SNP (G6813A) was detected in the exon 6 region, one SNP (G10340A) was detected in the exon 8 region, and one SNP (G10632A) was detected 3'UTR region. G6813A (V218I) and G10340A (R435H) were found to be missense mutations. Previous study have detected six SNP from five pig breeds (Italian Large White, Italian Duroc, Italian Landrace, Belgian Landrace, Pietrain), and two SNPs (G5011A, G8538A) were identified as missense mutations (V218I, R435H) (Davoli et al., 2011). These results were similar our data.

To investigate the effects of SNPs, the association of the PLIN2 genotypes were analyzed to determine the effects on variation in the economic traits in Berkshire pigs. Statistical analysis indicated that G6714C was significantly associated with the NPPC color score, G6813A, and G10340A significantly affected NPPC color score and NPPC marbling score, and G10632A significantly affected BF $(p<0.05)$. In the previous study, PLIN2 stimulates long chain fatty acid uptake and regulates metabolism of intracellular lipid droplets (Gao and Serrero, 1999; Conte et al., 2016; Polasik et al., 2019). And expression analysis showed the presence of PLIN2 transcripts in seven tested pig tissues with high expression found in adipose tissue and skeletal muscle (Davoli et al., 2011; Polasik et al., 2019). These results provide evidence that PLIN2 gene is a candidate gene for IMF.

Another studies showed that association between PLIN2 genotypes and growth traits in pigs; Polasik et al. (2019) 
showed that PLIN2 SNP is correlated with feed gain ratio and age at slaughter. Davoli et al. (2011) showed that its different variants are related to average daily gain, feed conversion ratio, lean cuts and ham weight estimated breeding values in Duroc pigs. And PLIN2 SNP is associated with early growth rate and carcass length in the Duroc pigs (Gol et al., 2016).

In this study, the efficiency of PLIN2 polymorphisms for Berkshire pigs economic traits was examined and suggested that polymorphisms might be important genetic factors influencing economic traits in Berkshire breeds.

\section{CONCLUSION}

The purpose of this study was to find a molecular marker for the improved economic traits in pig using candidate gene analysis. We identified four SNPs (G6714C, G6813A, G10340A, and G10632A) in the Berkshire pig PLIN2 gene. The G6714C was significantly associated with the NPPC color score, G6813A, and G10340A significantly affected NPPC color score and NPPC marbling score, and G10632A significantly affects BF $(p<0.05)$. These results indicate that PLIN2 may be candidate genes for economic traits.

\section{CONFLICTS OF INTEREST}

No potential conflict of interest relevant to this article was reported.

\section{ETHICS APPROVAL}

The study was approved by the Hankyong National University Animal Ethics Committee (No.2020-2).

\section{AUTHOR CONTRIBUTIONS}

\author{
Conceptualization: Hong Sik Kong \\ Data curation: Yesong Kim \\ Formal analysis: Yesong Kim \\ Funding acquisition: Hong Sik Kong \\ Investigation: Yesong Kim, Jiyeon Seong \\ Methodology: Yesong Kim, Jiyeon Seong \\ Project administration: Hong Sik Kong \\ Resources: Hong Sik Kong \\ Software: Yesong Kim, Yoonseok Lee \\ Supervision: Hong Sik Kong
}

Validation: Yesong Kim, Yoonseok Lee

Visualization: Yesong Kim

Writing - original draft: Yesong Kim, Jiyeon Seong

Writing - review \& editing: Jiyeon Seong, Yoonseok Lee, Hong Sik Kong

\section{AUTHOR'S POSITION AND ORCID NO.}

Y Kim, Masters's Course, https://orcid.org/0000-0001-8459-0519

J Seong, $\mathrm{PhD}$, https://orcid.org/0000-0003-0956-995X

Y Lee, Professor,

https://orcid.org/0000-0003-4803-5192

HS Kong, Professor, https://orcid.org/0000-0003-1144-016X

\section{REFERENCES}

Chang BH, Li L, Paul A, Taniguchi S, Nannegari V, Heird WC, Chan L. 2006. Protection against fatty liver but normal adipogenesis in mice lacking adipose differentiation-related protein. Mol. Cell. Biol. 26:1063-1076.

Cheong HS, Yoon DH, Kim LH, Park BL, Choi YH, Chung ER, Cho YM, Park EW, Cheong IC, Oh SJ, Yi SG, Park T, Shin HD. 2006. Growth hormone-releasing hormone (GHRH) polymorphisms associated with carcass traits of meat in Korean cattle. BMC Genet. 7:35.

Conte M, Franceschi C, Sandri M, Salvioli S. 2016. Perilipin 2 and age-related metabolic diseases: a new perspective. Trends Endocrinol. Metab. 27:893-903.

Davoli R, Gandolfi G, Braglia S, Comella M, Zambonelli P, Buttazzoni L, Russo V. 2011. New SNP of the porcine perilipin 2 (PLIN2) gene, association with carcass traits and expression analysis in skeletal muscle. Mol. Biol. Rep. 38:1575-1583.

Gao J and Serrero G. 1999. Adipose differentiation related protein (ADRP) expressed in transfected COS-7 cells selectively stimulates long chain fatty acid uptake. J. Biol. Chem. 274:16825-16830.

Gol S, Ros-Freixedes R, Zambonelli P, Tor M, Pena RN, Braglia S, Zappaterra M, Estany J, Davoli R. 2016. Relationship between perilipin genes polymorphisms and growth, carcass and meat quality traits in pigs. J. Anim. Breed. Genet. 133:24-30.

Kauffman RG, Eikelenboom G, van der Wal PG, Merkus G, Zaar M. 1986. The use of filter paper to estimate drip loss of porcine musculature. Meat Sci. 18:191-200.

Lee JH, Song KD, Lee HK, Cho KH, Park HC, Park KD. 2015. Genetic parameters of reproductive and meat quality traits in Korean Berkshire pigs. Asian-Australas. J. Anim. Sci. 28:1388-1393. 
Lee SH, Choi YM, Choe JH, Kim JM, Hong KC, Park HC, Kim BC. 2010. Association between polymorphisms of the heart fatty acid binding protein gene and intramuscular fat content, fatty acid composition, and meat quality in Berkshire breed. Meat Sci. 86:794-800.

McManaman JL, Bales ES, Orlicky DJ, Jackman M, MacLean PS, Cain S, Crunk AE, Mansur A, Graham CE, Bowman TA, Greenberg AS. 2013. Perilipin-2-null mice are protected against diet-induced obesity, adipose inflammation, and fatty liver disease. J. Lipid Res. 54:1346-1359.

National Pork Producer Council (NPPC). 2000. Pork composition and quality assessment procedures. NPPC, Des Moines, IA.
Oh JD, Lee KW, Jung IJ, Jeon GJ, Lee HK, Kong HS. 2011. Association of a single nucleotide polymorphism with economic traits in porcine uncoupling protein 3 gene. J. Life Sci. 21:155-158.

Polasik D, Kamionka EM, Tyra M, Żak G, Terman A. 2019. Analysis of FTO and PLIN2 polymorphisms in relation to carcass and meat quality traits in pigs. Ann. Anim. Sci. 19:71-83.

Rosenvold K and Andersen HJ. 2003. Factors of significance for pork quality-a review. Meat Sci. 64:219-237.

Tempfli K, Kiss B, Szalai K, Simon Z, Pongrácz L, Bali Papp Á. 2016. Differential expression of six genes in fat-type Hungarian Mangalica and other pigs. Arch. Anim. Breed. 59:259265. 